\section{Falsas Memórias - Fundamentos Científicos e suas Aplicações Clínicas e Jurídicas}

Stein LM, et al. Porto Alegre: Artes Médicas; 2010. 264p.

Por quase três décadas a comunidade científica tem buscado decifrar o fenômeno das falsas memórias, ou seja, circunstâncias em que pessoas normais se lembram de fatos específicos como se tivessem ocorrido durante determinados episódios de suas vidas, quando de fato não ocorreram naquele momento - ou jamais. Em virtude de suas implicações na área legal, tal fenômeno tem sido mais conhecido junto à comunidade forense. Neste sentido, avanços nessa área têm impactado, por exemplo, práticas de entrevistas para obtenção de testemunhos e técnicas de reconhecimento de suspeitos por testemunhas, o que, inclusive, gerou modificações na legislação de muitos países com relação a essas práticas. Por outro lado, no campo da psicoterapia, essa ainda é uma área pouco explorada, embora algumas técnicas psicoterapêuticas estejam sendo revistas em função do que se sabe hoje sobre os mecanismos que podem reduzir ou aumentar as falsas memórias.

Embora a literatura sobre as falsas memórias seja vasta, praticamente todas as pesquisas foram realizadas nos Estados Unidos, em inglês, e publicadas em periódicos e livros de língua inglesa. Neste contexto, o livro Falsas Memórias - Fundamentos Científicos e suas Aplicaçôes Clínicas e Jurídicas, organizado pela Profa. Dra. Lilian M. Stein e colaboradores, é o primeiro grande

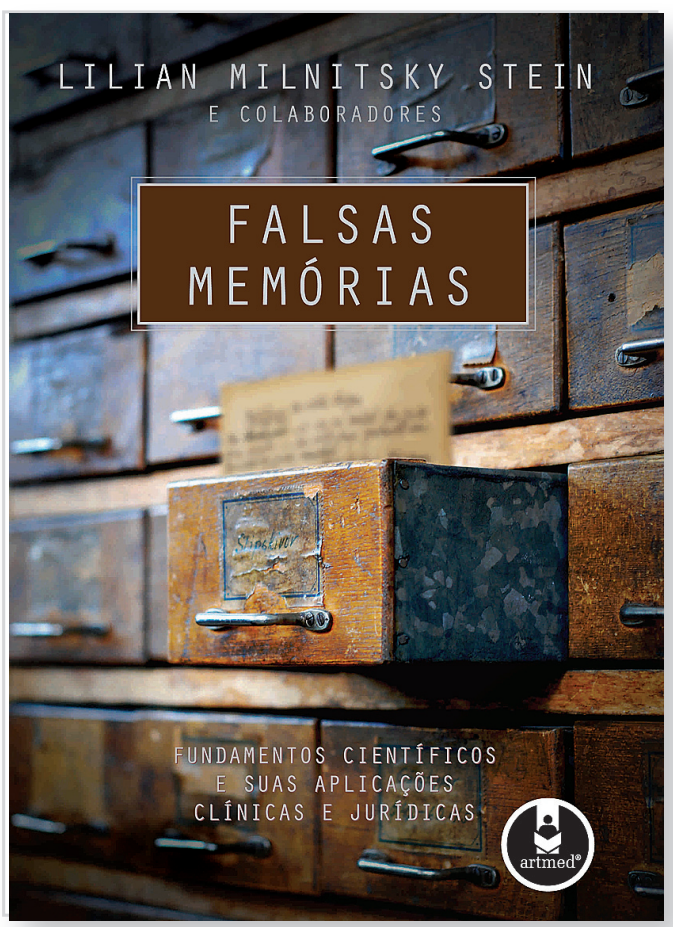

trabalho em língua portuguesa lançado na área. Não é por nada que dois dos maiores especialistas na área - Elisabeth F. Loftus, $\mathrm{PhD}$, e Charles J. Brainerd, PhD - se encarregaram de apresentar o livro aos leitores de língua portuguesa. Desde o início, já no seu prefácio, Dr. Brainerd retoma de modo muito didático a história da pesquisa na área, narrando o emblemático caso Estado de Nova Jersey versus Michaels, no qual uma atriz de 26 anos foi condenada por 115 acusações de abuso sexual e posteriormente libertada pela Suprema Corte em virtude da alta probabilidade dessas acusações serem frutos de falsas memórias induzidas nas crianças envolvidas.

A proposta do livro está sintonizada com o objetivo de disponibilizar à comunidade científica e profissional, tanto da Psicologia e Psiquiatria quanto do Direito, o acesso a uma literatura em língua portuguesa atualizada sobre as falsas memórias e seus desdobramentos para áreas aplicadas. Assim sendo, este livro está organizado em três partes. Na primeira, intitulada Fundamentos Científicos, são apresentados os principais conceitos e teorias explicativas das falsas memórias (Capítulo 1), os principais métodos de investigação experimental (Capítulo 2), e os avanços atuais que as neurociências têm propiciado para a compreensão deste fenômeno (Capítulo 3). As outras duas partes do livro alimentam-se desses fundamentos para apontar como o conhecimento científico sobre as falsas memórias tem sido direcionado tanto para alguns Tópicos Especiais (Parte II), quanto para Aplicaçôes Clinicas e Jurídicas (Parte III).

Com relação aos Tópicos Especiais, são abordados temas relacionados com o campo da emoção e falsas memórias (Capítulo 4) e de como a memória autobiográfica pode não estar imune às falsas memórias (Capítulo 5), além do fato de que as falsas memórias podem ser influenciadas por nossos processos cognitivos não-conscientes ou implícitos (Capítulo 6), ou por fatores relativos às diferenças individuais (Capítulo 7). Na terceira parte do livro, Aplicaçôes Clínicas e Jurídicas, são abordados temas como o testemunho infantil (Capítulo 8), as formas em que a repetição pode proteger as memórias das crianças da distorção (Capítulo 9), a questão de como as falsas memórias podem ser minimizadas em casos legais (Capítulo 10), a maneira como as memórias dos pacientes podem ser distorcidas durante a psicoterapia (Capítulo 11), e a chamada síndrome da falsa memória, que é associada à terapia com memórias recuperadas (Capítulo 12).

Acredito que o livro foi organizado e escrito de maneira a poder ser lido desde o aluno de graduação até o pesquisador interessado na área. Ele discute, de modo criterioso, muitos dos temas centrais da ciência moderna das falsas memórias e como os resultados das pesquisas na área podem ser aplicados nas esferas clínica e jurídica.

Rodrigo Grassi-Oliveira Grupo de Pesquisa Neurociência Cognitiva do Desenvolvimento, Programa de Pós-Graduação em PsicologiaCognição Humana, Pontifícia Universidade Católica do Rio Grande do Sul (PUCRS), Porto Alegre, RS, Brasil 